\section{RESPONSABILIDAD POR DAÑOS OCASIONADOS POR LA PRISIÓN PREVENTIVA*}

\author{
RESPONSIBILITY FOR DAMAGES CAUSED \\ BY PREVENTIVE DETENTION
}

\author{
RESPONSABILIDADE POR DANOS
SADOS PELA PRISÃO PREVENTIVA \\ RESPONSABILIDADE POR DANOS
CAUSADOS PELA PRISÃO PREVENTIVA
}

\section{RESUMEN}

El instituto de la prisión preventiva, aunque es un instrumento útil para la sociedad en su cometido de persecución del delito y del procesamiento de quienes los cometen, es de aplicación excepcional. La jurisprudencia ha admitido la procedencia de la indemnización para quien la sufre, cuando ha sido revocado el auto de prisión preventiva en razón de su dictado irregular o con arbitrariedad y, también, cuando la detención ha excedido un tiempo razonable, el cual se estima actualmente en dos años. Defendemos la inclusión de este deber de reparar entre los supuestos de responsabilidad del Estado por su obrar lícito y propiciamos el reconocimiento de los daños ocasionados en todos los casos en que haya sido ordenada, aún regularmente, contra una persona que luego no fue condenada en el proceso.

\footnotetext{
* Artículo de reflexión basado en la pesquisa realizada en el marco de las XXXIV Jornadas Nacionales de Derecho Administrativo, en la cual el autor participó como investigador y conferencista con respecto a la responsabilidad en el ámbito del Derecho público

a. Catedrático de Derecho Administrativo II de la Facultad de Derecho de la Universidad Nacional de Cuyo (Argentina), Director de la carrera de Doctorado de la misma institución, profesor de "Servicios públicos y regulación de la economía" en el Máster de la Universidad Austral (Buenos Aires). Miembro correspondiente de las Academias Nacional de Derecho y Ciencias Sociales de Córdoba y de Nicaragua, y del Instituto Argentino de Estudios Constitucionales y Políticos de Mendoza (Director en 2002-2004). Ministro integrante de la Suprema Corte de Justicia de la provincia de Mendoza (Argentina). Autor de seis libros, ha dirigido dos y ha publicado numerosos ensayos, capítulos de libro y artículos en revistas especializadas nacionales y extranjeras.
}

Alejandro Pérez Hualde ${ }^{a}$ aphualde@gmail.com Fecha de recepción: 15 de diciembre de 2014 Fecha de revisión: 9 de junio de 2015 Fecha de aceptación: 25 de junio de 2015
MISIÓN JURÍDICA

Revista de Derecho y Ciencias Sociales Bogotá, D.C. (Colombia)

Colaboradores Externos Internacionales Núm. 9, Año 2015

Junio - Diciembre, pp. 101 - 111

ISSN 1794-600X 


\section{PALABRAS CLAVES}

Responsabilidad del Estado, Prisión Preventiva, Derecho a la libertad, Reparación de daños, Debido proceso.

\begin{abstract}
The preventive detention institute is a useful instrument for society in its purpose of crime pursuit and the prosecution of whom commits it and it is of exceptional application. The jurisprudence has admitted the precedence of compensation to whom suffers from government tort when the formal order of imprisonment has been revoked because its irregular judgment or its arbitrariness and also when the detention has exceeded a reasonable time, that today is estimated in two years. We defend the inclusion of this duty of repairing among the supposed responsibilities of the State by its legal acts and we foster the acknowledgement of the damages caused in every case it has been ordered, even in a regular way, against a person that afterwards has not been convicted during the process.
\end{abstract}

\section{KEY WORDS}

State responsibility, preventive detention, right to freedom, damage reparation, due legal process.

\section{RESUMO}

O instituto da prisão preventiva, embora seja uma ferramenta útil para a sociedade na sua tarefa de fazer cumprir a lei e a repressão dos infratores, é uma aplicação excepcional. A jurisprudência tem admitido a validade da indenização para quem a sofre, quando a ordem de prisão preventiva for revogada em razão de seu caráter irregular ou arbitrário, e também quando a detenção exceder um prazo razoável, que é atualmente estimado em dois anos. Defendemos a inclusão deste dever de reparar entre os suspeitos de responsabilidade do Estado por seu ato lícito e de promover o reconhecimento de danos em todos os casos em que foram emitidos, mesmo regularmente, contra uma pessoa que não foi posteriormente condenada no processo.

\section{PALABRAS-CHAVE}

Responsabilidade do Estado; prisão preventiva; direito à liberdade; reparação de danos; o devido processo jurídico.

\section{Sumario}

I. Introducción. II. Antecedentes de doctrina y jurisprudencia. A) La jurisprudencia restrictiva. B) La apertura de la jurisprudencia a otros supuestos. 1. Morosidad judicial o indebida dilación de los procedimientos. 2. Arbitrariedad manifiesta o error grosero del auto de procesamiento seguido de absolución o sobreseimiento. C) Desde el Derecho Constitucional. D) Desde el Derecho Administrativo. IV. El fundamento constitucional. V.- Conclusiones.

\section{INTRODUCCIÓN}

El tema que abordamos tiene hoy plena vigencia, pues la inseguridad nos ha atacado a todos sin distinciones de clase social, económica, ni de ubicación geográfica. Presenciamos con preocupación las discusiones propias de la impotencia y la desorientación de quienes no encuentran una solución a un problema. Así es como hay quienes promueven el establecimiento de la pena de muerte, o el agravamiento de las penas, o la disminución de la edad de imputabilidad, o el aumento de patrulleros, etc., todas respuestas propias de la ignorancia que muchas veces demuestra nuestra dirigencia frente a las dificultades.

Es en medio de este confuso panorama en el que consideramos que es imprescindible reflexionar con más calma y visualizar los riesgos que asumimos en momentos en que la falta de respuesta adecuada nos puede llevar a cometer errores más graves que de costumbre.

La presión social y mediática que hoy se ejerce sobre los agentes de la policía de seguridad, sobre los fiscales y los jueces que intervienen en las primeras etapas del proceso penal, aquellas investigaciones realizadas al calor del dolor y del impacto mediático, cuando no de la exigencia popular expresada en manifestaciones públicas, ha incrementado notablemente el margen de error. La urgencia por "salir del paso", por calmar los primeros reclamos lógicos que imponen respuesta, cualquiera, lo antes posible -si es inmediata mejor-, ha provocado un mayor riesgo de equivocación en la realización de medidas tales como el allanamiento de domicilio y la detención preventiva. 
El accionar, muchas veces precipitado, ha llevado a cometer errores sustanciales en la imposición de la prisión preventiva en especial; muchas veces ordenada de un modo correcto, en cuanto a los aspectos estrictamente reglados de la decisión, pero equivocados en algunas ponderaciones de criterio que los funcionarios cometen en razón de aquellas presiones. Es frecuente que esto ocurra en perjuicio de personas quienes, por causa de su condición socio económica, deben vivir en barrios y villas donde no sólo quedan más expuestos a ser víctimas de la delincuencia a manos de sus vecinos, sino que, además, por proximidad de lugar y de trato, quedan sujetos a ser también víctimas de los errores naturales cometidos en las habituales persecuciones policiales que allí se desarrollan.

Esta situación nos ha llevado a considerar que es hoy, más que nunca, cuando hay que fortalecer una respuesta justa a esos numerosos casos en que alguien ha debido soportar la prisión preventiva. Aún en aquellos en que fue dictada contra una persona, con total ajuste a la normativa legal procesal que rige el instituto pero que, por cualquier causa, luego, no es condenada.

\section{Metodología}

Siguiendo las características propias de la investigación cualitativa, el presente estudio se enfocó en la realización de una línea jurisprudencial por medio de una consulta bibliográfica en torno a la prisión preventiva y la responsabilidad del Estado, realizando un análisis hermenéutico con base en las fuentes consultadas, específicamente leyes y pronunciamientos judiciales, y elaborando una comparación entre el espíritu de la norma y su desarrollo en la práctica judicial.

\section{ANTECEDENTES DE DOCTRINA Y JURISPRUDENCIA ${ }^{1}$}

La jurisprudencia, aunque lentamente, viene demostrando una evolución favorable a nuestra posición.

\subsection{La jurisprudencia restrictiva}

Hasta hace algunos años, la Corte Suprema de Justicia de la Nación (en adelante CSJN) fue decididamente adversa a reconocer indemnización alguna, por los daños causados por la prisión preventiva, a aquellas personas que la sufren y luego no son condenadas por distintas razones. Quizás el paradigma de esta tendencia sea la sentencia del 19/10/1995, recaída en el caso denominado "Balda, Miguel"2 .

De ese decisorio emana con claridad la siguiente doctrina judicial:

1. La actividad lícita del Estado ejercida a través del Poder Judicial no genera responsabilidad; los daños ocasionados por la prisión preventiva no constituyen uno de los supuestos de responsabilidad del Estado por los actos lícitos; las consecuencias deben ser soportadas por los particulares como costo inevitable resultante de la vida en sociedad y de una adecuada administración de justicia;

2. Es insuficiente, para fundar un caso de responsabilidad del Estado, la existencia posterior de sentencia absolutoria, puesto que la misma, en sí misma -y de por sí-, no descalifica el auto de prisión preventiva que sólo requiere indicios vehementes para considerar al sujeto como posible responsable del hecho que se investiga;

3. Por esa razón, para que exista responsabilidad del Estado, previamente, ese acto judicial, en el que se ordenó la prisión preventiva, debe haber sido revocado a través de una declaración de ilegitimidad; de otro modo, se alteraría la cosa juzgada.

Conforme a esta posición, por excepción, el único caso que da lugar al derecho a la indemnización del sujeto afectado, se configura cuando ha sido procesal y materialmente procedente el Recurso de Revisión de la cosa juzgada y quien fue condenado y privado de su libertad fue ulteriormente puesto en libertad, en razón de esa revisión. Es el supuesto mencionado expresamente en el art. 10 del Pacto

1. Nuevamente, tomaremos como modelo a seguir en el análisis el que fuera empleando por mi entonces colega Aída Kemelmajer de Carlucci en su voto, que acompañamos, en la causa $n^{\circ} 90.821$, caratulada: "Rojo, Laura C. en j. 149.241/10.102, Rojo, Laura C. c/Provincia de Mendoza $p /$ Daños y Perjuicios, s/inc", resuelta por la Sala I de la Suprema Corte de la provincia de Mendoza el 19 de mayo de 2008.

Fallos, 318:1990; también en revista "Iurisprudencia Argentina", t. 1996-III-155 y en revista "La Ley", t. 1996-B-311. Para una severa crítica a la doctrina mayoritaria del fallo, ver Gustavo Carranza Latrubesse, Responsabilidad del Estado por su actividad lícita, Buenos Aires, Abeledo-Perrot, 1998, p. 74 y ss, y en La doctrina de la Corte en el caso Balda, en "Foro de Córdoba", $n^{\circ} 42,1997, p .33$. 
Interamericano de Derechos Humanos y en numerosas constituciones y leyes provinciales.

Si bien ha sido criticada por la doctrina ${ }^{3}$, esta jurisprudencia estaba fuertemente influenciada por las ideas expuestas por el maestro Marienhoff, para quien sólo puede hablarse de error judicial que genera indemnización si existe condena y posterior juicio de revisión, lo que comprueba la inocencia de quien sufrió la prisión preventiva.

En otras palabras, la responsabilidad del Estado se presentaría -de hecho-, para esta posición estricta, únicamente cuando se dieran los elementos necesarios para determinar fehacientemente la responsabilidad personal del juez. No obstante, el voto en minoría de los Dres. Fayt, Belluscio y Petracchi, en la causa "Balda" abrió camino a una posición de apertura.

\subsection{La apertura de la jurisprudencia a otros supuestos}

Un sector ampliamente mayoritario de la actual jurisprudencia y la doctrina nacional afirma que, como regla, el dictado de la prisión preventiva configura una facultad judicial sometida a pautas abiertas $\mathrm{y}$, consecuentemente, si, en abstracto, la decisión judicial encuadra en las previsiones legales, la ulterior declaración de inocencia es insuficiente per se para disponer la reparación de los daños causados.

Sin embargo, esa indemnización es viable en los supuestos fundados en principios generales de rango constitucional; esos casos son: a) cuando se presente una dilación indebida de los procedimientos; b) ante una arbitrariedad manifiesta del auto de procesamiento seguida de la ulterior absolución o sobreseimiento del imputado; y c) cuando la prisión preventiva obedezca a prueba ilegítimamente obtenida por la policía.

\subsubsection{Morosidad judicial o indebida dilación de los procedimientos}

El leading case en esta materia es la sentencia de la CSJN del 1/11/1999 recaída en la causa "Rosa, Carlos"4 .

3. Diego Pablo Llinás, La cosa juzgada: impedimento para la procedencia de la responsabilidad del Estado por su actividad jurisdiccional, en "Derecho Administrativo", año 15, 2003, Depalma Lexis Nexis, Buenos Aires, p. 426.
Se trata de un caso en el que el imputado fue absuelto por el beneficio de la duda, pero había estado privado preventivamente de su libertad durante cuatro años; la mayoría del tribunal consideró que el mantenimiento de la medida cautelar en los dos primeros años de detención constituyó el producto del ejercicio regular del servicio de justicia; mas, a partir de esos dos años, el procedimiento había excedido razonables pautas temporales.

El tribunal valoró que después de los dos años, el imputado había peticionado reiteradamente la excarcelación, habiéndosele denegado mediante el empleo de afirmaciones genéricas y dogmáticas que se contradecían con las concretas circunstancias de la causa; también tuvo en cuenta la jurisprudencia de la Corte Interamericana de Derechos Humanos en torno a la dilación indebida de los procedimientos.

La solución cuenta con la adhesión de la, prácticamente, unanimidad de la doctrina nacional ${ }^{5}$; y es razonable, pues con la incorporación de los Tratados de Derechos Humanos en el art. 75 inc. $22 \mathrm{CN}$, ya no hay lugar a discrepancias respecto de la reparación de daños causados por la dilación indebida de los procedimientos seguidos, mientras el imputado se encuentra bajo prisión preventiva, supuesto aceptado por la Corte Europea de Derechos Humanos hace ya muchos años.

No obstante, nuestro país sufrió una condena de la Corte Interamericana de Derechos Humanos en el caso "Bayarri vs. Argentina", por haber prolongado irrazonablemente una prisión preventiva ${ }^{6}$.

Podemos afirmar que la doctrina de nuestra CSJN de este momento es todavía la de no reconocer responsabilidad sino cuando existe irregularidad o arbitrariedad en el acto de imposición de la prisión preventiva y cuando se presenta un exceso en el tiempo insumido por la

4. Fallos, 322:2683; también en revista "La Ley", t. 2000-D, p. 557 y en "Jurisprudencia Argentina", t. 2000-III, p. 246; con comentario de Jorge Mosset Iturraspe, Daño injusto por prolongación indebida de la prisión preventiva, y en revista "El Derecho", t. 187, p. 340.

5. Entre otros ver Emilio Ibarlucía, La responsabilidad del Estado frente a la absolución del detenido o a la revocación de la prisión preventiva, en El Derecho, t. 176-755.

6. Corte Internacional de Derechos Humanos, Serie C, № 187, sentencia del 30 de octubre de 2008. 
medida; sin aventurar un plazo estricto, pero que está estimado en dos años como máximo.

\subsubsection{Arbitrariedad manifiesta o error grosero del auto de procesamiento seguido de absolución o sobreseimiento}

En realidad, esta excepción a la inmunidad del Estado había sido ya admitida por la CSJN hace casi veinte años, aunque finalmente la demanda se rechazó porque se consideró que la situación fáctica no se subsumía en los presupuestos exigidos ${ }^{7}$.

En otro precedente, la CSJN reiteró su doctrina afirmando que

(...) el Estado sólo puede ser responsabilizado por error judicial en la medida en que el acto jurisdiccional que origina el daño sea declarado ilegítimo y dejado sin efecto, pues antes de ese momento el carácter de verdad legal que ostenta la sentencia pasada en autoridad de cosa juzgada impide, en tanto se mantenga, juzgar que hay error. Lo contrario importaría un atentado contra el orden social y la seguridad jurídica ${ }^{8}$.

La búsqueda del error, que abra la revisión, como único supuesto para basar la responsabilidad del Estado lleva a que el mismo fallo sostenga la inexistencia de salida; dice que

(...) si para escapar al peligro del error posible hubiera de concederse recurso de las decisiones de la Corte, para escapar a idéntico peligro, habría que conceder recurso de las decisiones del tribunal que pudiera revocar las decisiones de la Corte, y de éste a otro por igual razón, estableciendo una serie que jamás terminaría porque jamás podría hallarse un Tribunal en que no fuera posible el error?

El máximo Tribunal descarta la responsabilidad del Estado por actividad lícita, pues se sostiene que "tampoco podría responsabilizarse al Estado por su actividad lícita, pues los actos judiciales son ajenos por su naturaleza a este tipo de

7. CSJN, 4/11/1986, en revista "El Derecho", t. 122, p. 345, con nota de Juan Carlos Cassagne, La responsabilidad del Estado por error judicial.

8. Fallos, 321:1712; expte. no L.241.XXIII, "López, Juan de la Cruz y otros c/ Corrientes, provincia de s/daños y perjuicios", del 11 de junio de 1998.

9. Ibídem resarcimiento"... y ello porque en el caso de las sentencias y las demás actuaciones judiciales

(...) no se trata de decisiones de naturaleza política para el cumplimiento de fines comunitarios, sino de actos que resuelven un conflicto en particular. Los daños que puedan resultar del procedimiento empleado para dirimir la contienda, si no son producto del ejercicio irregular del servicio, deben ser soportados por los particulares, pues son el costo inevitable de una adecuada administración de justicia ${ }^{10}$.

Said recuerda el voto de Argibay en el fallo "Andrada", el cual sostiene que

(...) si el acto que es el antecedente inmediato de los efectos que se reputan dañosos es lícito, también lo son sus consecuencias, pues, como lo enseñara Alfredo Orgaz, 'el acto y su consecuencia (inmediata o mediata previsible, que son las únicas que la ley imputa al agente, arts. 903 y 904 civiles) constituyen una unidad inescindible, al punto de que el acto separado de su consecuencia es inimaginable, y ésta deja de ser ella misma con independencia de aquél. Si el acto es lícito, tiene que serlo también la consecuencia, si es ilícito ésta ha de participar de idéntica naturaleza' ('La ilicitud', Córdoba-Buenos Aires, 1973, p. 34-35). Esta circunstancia bastaría para rechazar la demanda por los daños derivados de la prisión preventiva cumplida"11.

Ahora bien, para determinar si el auto de procesamiento es el resultado de error judicial grosero, si es arbitrario, o carece de sustento lógico, hay que tener en cuenta los elementos probatorios con los que el juez de instrucción contaba, y no los existentes en el plenario o debate, ya que el primero sólo necesita reunir medios de convicción suficientes para estimar que existe un hecho delictuoso.

En estos últimos años, la CSJN se muestra más flexible en la verificación de esa arbitrariedad o error inexcusable. Así, por ejemplo, se ha dispuesto que se debe indemnizar los daños sufridos por la privación de la libertad ambulatoria durante dos años y cuarenta y seis días

\section{Ibídem.}

11. Considerando $7^{\circ}$ de su voto en expte. $n^{\circ}$ A.901.XXXVI, caratula "Andrada, Roberto Horacio y otros c/ Buenos Aires, Provincia de y otros s/ daños y perjuicios", sentencia del 5 de septiembre de 2006. 
(...) si se acreditó suficientemente el cumplimiento irregular del servicio del personal de la policía que tenía a su cargo la investigación del delito de tráfico de estupefacientes por el cual se lo acusó y del que fue absuelto, siendo que esas irregularidades surgen de la declaración de nulidad de la orden de allanamiento y de los actos que fueron consecuencia directa y necesaria de éste" ${ }^{12}$.

Algunos autores coinciden con la solución, pero en una posición de mayor apertura, proponen no exigir como requisito sine qua non que el imputado haya sido declarado inocente.

\subsection{Desde el Derecho Constitucional}

El maestro Germán Bidart Campos propició una apertura aún mayor. Fundó su posición no sólo en las normas antes reseñadas, sino en el art. 9.5 del Pacto de Derechos Civiles y Políticos que prescribe: "Toda persona que haya sido ilegalmente detenida o presa tendrá el derecho efectivo a obtener reparación". Esta norma, explicó, a diferencia de la Convención Interamericana, apunta a una "privación ilegal de la libertad, sin referencia alguna a la sentencia o decisión que pueda haberla dispuesto erróneamente".

\section{Más adelante expresa:}

Es verdad que la administración de justicia precisa, para ser impartida eficazmente, que en muchas causas penales una persona sea -a veces- privada transitoriamente de su libertad; sin embargo, no queda duda de que esa privación es una limitación fortísima al derecho a la libertad ambulatoria y a la presunción de inocencia. Soportar tan grave limitación puede ser necesario en ciertas situaciones para contribuir a la buena administración de la justicia penal, lo que conduce a admitir que las limitaciones razonables a los derechos son una premisa elemental de todo Derecho Constitucional democrático, porque ningún derecho es absoluto ni dispone de espacio para ejercerse anti funcionalmente. Todo esto es verdad, pero también lo es que la circunstancia de que al momento de disponerse y cumplirse la prisión preventiva haya habido suficientemente razonabilidad para imponerle al inculpado tal sacrificio, no configura obstáculo para el reconocimiento posterior de que,

12. CSJN, 27/5/2004, "Cura, Carlos A c/Provincia de Bs. As.", en "Revista de Responsabilidad Civil y Seguros", año 2004, n 8, p. 70. una vez beneficiado al término del proceso con el sobreseimiento o con la absolución, concurre mérito bastante para hacerle efectivo su derecho a la reparación. Ello por el perjuicio irrogado a su libertad, consistente en haber estado temporalmente privado de ella. Si atendemos a una primera etapa procesal, no vacilamos en decir que hay que coadyuvar al ius persequendi y al ius poenendi, en conjunción con razones de seguridad y solidaridad social. Pero cuando en la etapa final del proceso penal sobreviene como verdad material $\mathrm{u}$ objetiva el sobreseimiento o la absolución de quien sufrió privación preventiva de la libertad y cooperó así con la administración de justicia, reaparece la idea madre"... "No es menester suponer que cuando el derecho a la reparación se torna viable haya que negar la licitud originaria del acto judicial de prisión preventiva. Basta con admitir que después del sobreseimiento o la absolución aquella licitud, sin convertirse en ilicitud sobreviniente, ha de ceder frente a la prioridad axiológica del derecho a la libertad". Y concluye: "Damos por cierto que todo esto compone un repertorio general que no ha de aplicarse como una etiqueta a cada caso a todos sin discriminación alguna. Tal vez haya que distinguir, por ej., la reparación a que puede tener derecho quien obtiene sobreseimiento o absolución por el beneficio de la duda, de la que conviene otorgar cuando queda claramente probado que la autoría del delito no le es imputable al procesado $^{13}$.

Desde el mismo campo del Derecho Constitucional se alzan otras voces como la de Mario Midón quien señala cómo

(...) en ese esquema donde la mala suerte desplaza al derecho se introduce la singular idea de que una privación injustificada equivale a una carga pública y, por ende, un habitante de la Nación está llamado a sobrellevar con tolerada mansedumbre de vasallo este tipo de atropellos ${ }^{14}$.

Sobre estas bases constitucionales construimos nuestra posición.

13. Germán Bidart Campos, ¿Hay un derecho a reparación por la privación preventiva de libertad?, en "Revista de Derecho de Daños", $n^{\circ}$ 9, p. 227 y ss, y en Tratado elemental de derecho constitucional argentino, t. II-A, Ediar, Buenos Aires, 2003, p. 200. En similar sentido ver Fernando Sagarna, La responsabilidad del Estado por la detención preventiva de personas, en revista "La Ley", t. 1996-E, p. 890; y Carlos Ghersi, Responsabilidad del Estado por actos lícitos jurisdiccionales, en revista "Jurisprudencia Argentina", t. 1994-I, p. 297.

14. Ver La mala suerte de una detención y la imposibilidad de su reparación, en revista "La Ley", t. 2006-B, p. 53. 


\subsection{Desde el Derecho Administrativo}

Desde el campo del Derecho administrativo, José Said ${ }^{15}$ sostiene la posición más amplia, en el sentido de desprender la responsabilidad de los detalles de legalidad y procedencia de la orden de prisión preventiva o de su duración y sostenerse únicamente sobre el resultado de condena, o no condena, al final del proceso judicial criminal. Si el reo no es condenado, procede la indemnización de la prisión preventiva en todos los casos.

Afirma Said que deben tenerse en cuenta los siguientes argumentos:

1. el art. 18 de la Constitución Nacional hace responsable al juez por la mortificación innecesaria de los detenidos;

2. la absolución o sobreseimiento de un detenido demuestra, finalmente, que la prisión preventiva fue una mortificación injustificada;

3. el Estado debe responder por los perjuicios ocasionados por la detención preventiva de quienes no son finalmente condenados, sea por actividad lícita o, bajo ciertas circunstancias, por actividad ilegítima; $\mathrm{y}$

4. no resulta acorde a la axiología e ideología de la Constitución reparar la afectación de la propiedad por actividad estatal lícita y no hacerlo con las lesiones a la libertad cuando la causa es la actividad judicial igualmente lícita.

Acertadamente destaca Said, que si el Estado, en este caso Poder Judicial y Ministerio Público,

dispone, por un lado, mantener privado de su libertad durante meses o años a un ser humano sin que exista una condena previa, y, por otro, no logra demostrar su culpabilidad; y si es el mismo Estado quien decide qué recursos humanos, materiales y normativos aplicar para investigar y sancionar la comisión de los hechos que se denuncian o persiguen de oficio; es posible exigirle

15. Conferencia brinda en las "III Jornadas Rosarinas de Derecho Administrativo Dr. Antonio Pedro Chede", desarrolladas los días 26 y 27 de junio de 2008 en la Ciudad de Rosario, organizadas por la Carrera de Especialización en Derecho Administrativo de la Facultad de Derecho de la Universidad Nacional de Rosario; la ponencia se titula: "..hará responsable al juez que la autorice" (consideraciones sobre la responsabilidad del Estado por la prisión preventiva en todos los casos de absolución o sobreseimiento), publicada en revista "Jurisprudencia Argentina" del 31 de diciembre de 2008. que asuma la responsabilidad, constitucionalmente impuesta, de reparar o indemnizar a quienes resultaron víctimas de sus decisiones. Decisiones éstas que afectaron la libertad de personas y que no resultaron beneficiosas para la sociedad, pues ningún beneficio para la comunidad puede concebirse del hecho de privar de su libertad a personas inocentes ${ }^{16}$.

Hoy está fuera de toda discusión el severo déficit de gestión judicial que se traduce en una inadmisible morosidad en los procedimientos, tanto civiles, como laborales y también penales.

\section{EL FUNDAMENTO CONSTITUCIONAL}

Adelantamos que compartimos la posición de los constitucionalistas, y de Said, y procuramos contribuir sobre la base de los fundamentos que sirven de soporte a la responsabilidad del Estado por su accionar lícito, pues no vemos diferencia, en los fundamentos, respecto a los otros supuestos del terreno de acción de los poderes Ejecutivo y Legislativo.

A) La explicación del alto Tribunal en el sentido de que el Poder Judicial no toma decisiones de naturaleza política y que, por esa sola razón, no asume responsabilidad por su accionar lícito no resulta convincente. El Poder Judicial aplica la prisión preventiva a personas sobre las que no le consta su culpabilidad; priva de la libertad sobre el cumplimiento de requisitos pero asumiendo la posibilidad cierta de que ella sea injusta, pues carece de la certeza -inexigible pero necesaria- para justificar la asunción del daño por quien resulta víctima.

En ese rumbo se encuentra una afirmación del abogado patrocinante en el proceso "Rojo", quien señala que

(...) si la razón es que la actividad judicial persigue un beneficio social no cabría distinguir entre la actividad legislativa y la judicial y la ejecutiva $y$, consecuentemente, hay reparación cuando se trata de un daño de especial gravedad, que excede la tolerancia de lo que la vida en sociedad impone a todo ciudadano"17.

16. Op. Cit. Said, José.

17. Op. Cit. "Rojo, Laura C. en j. 149.241/10.102, Rojo, Laura C. c/ Provincia de Mendoza p/Daños y Perjuicios, s/inc", resuelta por la Sala I de la Suprema Corte de la provincia de Mendoza el 19 de mayo de 2008 
B) Ahora bien, consideramos que los tormentos que deben soportar los detenidos en prisión preventiva no son el fundamento de la reparación por cuanto éstos tampoco son justificables en los condenados $\mathrm{y}$, en definitiva, se trata de una responsabilidad por omisión -inconstitucional- del Estado en su deber concreto de tener cárceles sanas y limpias. Los tormentos son base de reclamación para todos, para los detenidos en forma preventiva y también para los condenados.

C) Los razonamientos dirigidos a establecer la razonabilidad en el acto que ordenó la prisión preventiva y si la liberación del detenido se produce por absolución, sobreseimiento, beneficio de la duda, o error judicial demostrado luego por vía del Recurso de Revisión, en realidad sólo tienden a determinar el grado de responsabilidad personal del juez y del sistema judicial, y si se ha incurrido o no, y en qué medida, en mal desempeño; pero no tiene nada que ver con los derechos conculcados del detenido; esto es así, al menos, si es verdad que hemos abandonado la vieja etapa de tomar como base a la antijuridicidad para sostener la responsabilidad del Estado.

D) El tiempo que insume la estrategia defensiva del detenido tampoco puede ser argüida en su contra; aún cuando hubiera sido errónea, si después se decretó la falta de mérito o el sobreseimiento no es coherente sostener que deba padecer la prolongación de los tiempos judiciales que ha insumido la tramitación de su defensa. El hecho de haber recurrido el auto de prisión preventiva, o de no haberlo hecho; de haber sido o no exitoso, etc., no puede contarse en contra de quien finalmente resultó excluido de condena. Sólo debe analizarse la posibilidad de reclamo en el caso en que el detenido haya actuado con dolo o culpa grave induciendo a error al Tribunal, por encubrimiento, por colaboración con algún tercero, o por alguna otra razón que debería ser probada en el caso concreto.

E) La prisión preventiva es un instituto útil para asegurar el sometimiento al proceso del sujeto que aparece prima facie como autor del delito que se investiga; su manejo es excepcional y, según la última doctrina, sólo debe imponerse cuando hay fundadas razones para pensar que el sospechoso se sustraerá al proceso. Como destaca Gelli, "la detención preventiva, cautelar, de los sometidos a juzgamiento estaba prevista desde los orígenes del proceso constituyente argentino aunque, desde luego, sujeta a las garantías y respeto debido a la persona humana y a su dignidad" 18.

Más aun, en su voto en la causa "Robles", el ministro Gustavo Bossert sostiene que "la detención preventiva es una necesidad del ejercicio de un deber primario del Estado impuesto por la defensa social a través de la persecución del delito y resulta consentida dentro de situaciones razonables y según la naturaleza del caso y la ilicitud de la conducta del procesado ${ }^{19}{ }^{\prime \prime}$.

Como instrumento tiene sus requisitos formales y materiales de aplicación y puede ser ordenada en forma correcta y procedente. No estamos en contra de la prisión preventiva como instrumento para apoyar la investigación eficiente en determinados casos, a criterio del juez y dentro de los requerimientos establecidos por la ley.

F) Sea como fuere que sea ordenada, la prisión preventiva ocasiona daños inevitables a quien es el sujeto destinatario de ella. Esos daños serán justos o injustos, justos si el resultado del proceso es de condena a quien está incurso en la privación de la libertad para asegurar el éxito del proceso. Será injusto el daño que deba afrontar quien es inocente en el proceso, y es inocente todo aquél que no fue condenado.

Dice la Corte de San José de Costa Rica que la prisión preventiva

(...) es la medida más severa que se puede aplicar a la persona acusada de delito, por lo cual su aplicación debe tener carácter excepcional, limitado por el principio de legalidad, la presunción de inocencia, la necesidad y proporcionalidad, de acuerdo con lo que es estrictamente necesario en una sociedad democrática [porque se trata de] una medida cautelar, no punitiva ${ }^{20}$.

G) Producido un daño, demostrada la injusticia en razón del resultado del proceso, no se ve la razón para eludir la reparación de quien debió sufrirlo. Lo contrario implica castigarlo por el sólo

18. María Angélica Gelli, El plazo razonable de la prisión preventiva y el valor de la jurisprudencia internacional (en el caso "Acosta"), en revista "La Ley", Buenos Aires, lunes 30 de agosto de 2012, La Ley, t. 2012-D.

19. CSJN, expte. no R. 134. XXXIV, causa "Robles, Ramón Cayetano c/ Buenos Aires provincia de", del 18 de julio de 2002.

20. Caso "Bayarri vs. Argentina". 
hecho de haber encuadrado en los requerimientos técnicos procesales, aunque fuera inocente; podríamos agregar irónicamente: "por algo será"...

Por lo tanto, corresponde pagar el daño a quien no ha sido condenado en el proceso en razón del cual sufrió prisión preventiva; y esa reparación de los daños ocasionados corresponde que sean calculados por el Estado entre los costos necesarios exigidos por ese instrumento imprescindible para la persecución penal y el eficaz desarrollo de las investigaciones.

Es cierto que la culminación sin condena del proceso penal respecto del detenido preventivamente no demuestra necesariamente que su detención haya sido totalmente injustificada, desde el punto de vista del remedio preventivo y sus requisitos. Si no hubo condena, el detenido es inocente y no existe causa jurídica para que se vea obligado a soportar el daño en razón de un instituto establecido en beneficio de toda la comunidad.

H) El costo inevitable de la prisión preventiva como instrumento necesario para la investigación penal eficaz no puede ser asumido por la víctima de esa prisión preventiva sin afectar notablemente el art. 16 CN. Debe ser asumido por la comunidad, que necesita de esos mecanismos hasta que se inventen otros más eficaces.

Estamos en desacuerdo con el fallo y de acuerdo con Said. Es decisión de política de seguridad:

La decisión de encarcelar personas durante la investigación y persecución de los delitos por los órganos estatales, responde a una medida de política gubernativa (establecida en las leyes que regulan la persecución penal) dirigida a atender un interés social o comunitario, según lo interpreta el Poder Legislativo en el ámbito de su competencia ${ }^{21}$.

La CSJN dice: "Los daños que puedan resultar del procedimiento empleado para resolver la contienda, si no son producto del ejercicio irregular del servicio, deben ser soportados por los particulares, pues son costo inevitable de una adecuada administración de justicia"22. Y critica

\section{Op. Cit. José Said.}

22. CSJN, Causa "BALDA", M. A. c/ Buenos Aires Provincia s/ Daños y perjuicios", B.2.XXIII, originario. Opinión personal del Dr. Sodero Nievas.
Said: "El carácter inevitable que la Corte señala en los daños a la libertad, la integridad, la honra, la familia, la identidad, la propiedad, etc., que el Estado ocasiona a un ser humano al disponer coactivamente su detención preventiva, no permite inferir que ellos deban ser considerados 'irreparables' pecuniariamente" ${ }^{23}$.

Estamos frente a un razonamiento viciado, como es inevitable lo paga la víctima; no es ese un criterio válido de atribución. Algo es evidente: los daños sufridos en un ámbito de cumplimiento de prisión preventiva, no son -en modo alguno- del tipo de aquellas incomodidades normales, propias de la convivencia, que todos sufrimos y debemos sufrir.

\section{CONCLUSIONES}

Conocemos las posiciones de quienes consideran inaceptable un grado de responsabilidad civil desvinculado de la actuación irregular o ilícita del autor del daño ${ }^{24}$. Pero en el ámbito del Derecho Público encontramos las raíces de la responsabilidad por el accionar lícito ya en la misma Constitución de 1853 cuando en su art. 15 ordena expresamente la indemnización de quienes se vieran perjudicados por la declaración de libertad de los esclavos.

Ya en estos tiempos, en el caso "El Jacarandá", la CSJN -con su composición actual- sostiene, en un posible obiter dictum, que

(...) cabe recordar que cuando la actividad lícita de la autoridad administrativa, aunque inspirada en propósitos de interés colectivo, se constituye en causa eficiente de un perjuicio para los particulares -cuyo derecho se sacrifica por aquel interés general-, esos daños deben ser atendidos en el campo de la responsabilidad del Estado por su obrar lícito"... "no hay, como principio, fundamento para limitarlo al daño emergente con exclusión del lucro cesante, esto es, de las ventajas económicas esperadas de acuerdo a probabilidades objetivas estrictamente comprobadas" 25 .

\section{Op. Cit.José Said}

24. Marcelo J. López Mesa, Elementos de la responsabilidad civil. Examen contemporáneo, Pontificia Universidad Javeriana, Biblioteca Jurídica Dike, Bogotá, 2009, p. 331.

25. Fallos, 328:2654; el Tribunal hace mención del caso "Cachau" (Fallos, 316:1335) que versó sobre responsabilidad por el accionar lícito del Estado en diversas causas iniciadas por perjudicados por la acción gubernamental de desviación de aguas de inundación en la provincia de Buenos Aires. 
No encontramos diferencias de situación que justifiquen un tratamiento diferenciado a los distintos poderes del Estado. Máxime cuando en el caso se presentan todos los elementos que respaldan la responsabilidad por su accionar lícito a través de -como nosotros defendemoscualquiera de sus poderes:

1. existencia de un daño resarcible (más allá de aspectos de reparación imposible);

2. una conducta estatal lícita;

3. comprobación de la existencia de un sacrificio especial en el afectado;

4. vinculación de estricta causalidad entre el daño y la conducta estatal;

5. ausencia de un deber jurídico de soportar ese daño.

La jurisprudencia hoy reinante es inadmisible si la confrontamos con las nuevas tendencias del Derecho Constitucional, en materia de garantías, y del Derecho Administrativo, que ha abandonado las actitudes autoritarias, y que se compromete con su rol de garante de las libertades fundamentales de todos los miembros de la comunidad.

Un adecuado encuadramiento legal del sistema de reparación, que no pretenda desvirtuar la responsabilidad en sus objetivos, podría establecer parámetros razonables que permitan enfrentar este nuevo "costo material" que nos exige la seguridad de todos.

Se impone un enfoque inverso del esquema de reparación. Hemos sostenido en la Suprema Corte de Mendoza ${ }^{26}$ que:

la teoría de la responsabilidad civil en su actual concepción doctrinaria tiende a superar el concepto clásico que ponía el acento en el autor del ilícito, en la obligación del responsable de indemnizar el perjuicio ilícitamente causado, para ser considerado como un derecho de la víctima a obtener la reparación integral

26. Voto en expte no 101477 , caratulado "Fader Mora, Carlos Enriquec/ provincia de Mendoza p/D. y P'" del 11 de abril de 2012.

27. Voto de Aída Kemelmajer de Carlucci en Libro de Sentencias, t. 417, p.36. del daño injustamente sufrido. Del débito de responsabilidad, concebido como obligación del dañador de resarcir a la víctima, se pasa a privilegiar el crédito de indemnización nacido en cabeza de ésta con motivo del acaecimiento del daño que injustamente sufre, supuesto de hecho necesario que le otorga legitimación para reclamar su reparación. El cambio más importante que se advierte en el tema que nos ocupa es el del emplazamiento del derecho a la reparación como derecho constitucional ${ }^{27}$.

Un debido tratamiento legislativo podría, por ejemplo, establecer el carácter estrictamente personalísimo de la acción de reclamo de daños en este supuesto; también podría prever el supuesto caso en que una prisión preventiva no culmine en condena en ese mismo proceso, pero sí resulte condenado en otro realizado en forma paralela en la misma o en otra jurisdicción. Indudablemente, deberían establecerse distintos instrumentos y aspectos técnicos propios del Derecho Penal.

Consideramos que el legislador debe hacerse cargo del tema y establecer las pautas para una determinación del daño y de su reparación en forma adecuada y rápida, de tal modo de brindar una respuesta encuadrada en los requerimientos mínimos de un sistema de justicia que debe hacerse cargo del costo del instituto de la prisión preventiva, mientras no logre establecer uno más eficaz y que produzca menos daños a quien, en definitiva, por cualquier causa, resulta no condenado. 


\section{BIBLIOGRAFÍA}

- BIDART CAMPOS, Germán, ¿Hay un derecho a reparación por la privación preventiva de libertad?, en "Revista de Derecho de Daños", $n^{\circ}$ 9, p. 227.

- Tratadoelementaldederechoconstitucional argentino, t. II-A, Ediar, Buenos Aires, 2003.

- CARRANZA LATRUBESSE, Gustavo, Responsabilidad del Estado por su actividad lícita, Buenos Aires, Abeledo-Perrot, 1998.

- La doctrina de la Corte en el caso Balda, en "Foro de Córdoba", n 42, 1997.

- CASSAGNE, Juan Carlos, La responsabilidad del Estado por error judicial, en revista "El Derecho", t. 122, p. 345.

- GELLI, María Angélica, El plazo razonable de la prisión preventiva y el valor de la jurisprudencia internacional (en el caso "Acosta"), en revista "La Ley", Buenos Aires, lunes 30 de agosto de 2012, La Ley, t. 2012-D.

- GHERSI, Carlos, Responsabilidad del Estado por actos lícitos jurisdiccionales, en revista "Jurisprudencia Argentina", t. 1994-I, p. 297.

- IBARLUCÍA, Emilio, La responsabilidad del Estado frente a la absolución del detenido o a la revocación de la prisión preventiva, en El Derecho, t. 176-755.

- LÓPEZ MESA, Marcelo J., Elementos de la responsabilidad civil. Examen contemporáneo, Pontificia Universidad Javeriana, Biblioteca Jurídica Dike, Bogotá, 2009.

- LLINÁS, Diego Pablo, La cosa juzgada: impedimento para la procedencia de la responsabilidad del Estado por su actividad jurisdiccional, en "Derecho Administrativo", año 15, 2003, Depalma Lexis Nexis, Buenos Aires.

- MIDÓN, Mario, La mala suerte de una detención y la imposibilidad de su reparación, en revista "La Ley", t. 2006-B, p. 53.

- MOSSET ITURRASPE, Jorge, Daño injusto por prolongación indebida de la prisión preventiva, y en revista "El Derecho", t. 187, p. 340.

- SAID, José, “...hará responsable al juez que la autorice" (consideraciones sobre la responsabilidad del Estado por la prisión preventiva en todos los casos de absolución o sobreseimiento), en revista "Jurisprudencia Argentina" del 31 de diciembre de 2008.

- SAGARNA, Fernando, La responsabilidad del Estado por la detención preventiva de personas, en revista "La Ley", t. 1996-E, p. 890. 